\title{
The contribution of Helicobacter pylori to excess gastric cancer in Indigenous and Pacific men: a birth cohort estimate
}

\author{
Andrea M. Teng ${ }^{1} \cdot$ Tony Blakely $^{1} \cdot$ Michael G. Baker $^{1} \cdot$ Diana Sarfati $^{1}$
}

Received: 20 September 2016/ Accepted: 8 November 2016/Published online: 16 November 2016

(c) The International Gastric Cancer Association and The Japanese Gastric Cancer Association 2016

\begin{abstract}
Background The reasons for higher gastric cancer incidence rates in indigenous populations are debated.

Methods We quantify the role of Helicobacter pylori in excess gastric cancer incidence in Māori and Pacific men in New Zealand. Age-standardized gastric cancer rate ratios for 1981-2004 were calculated in Māori and Pacific men compared with European/other men born in 1926-1940 and in 1941-1955. Rate ratios were then compared with those restricted to $H$. pylori prevalent populations.

Results $H$. pylori contributed substantially to excess gastric cancer incidence in Māori men $(50 \%, 61 \%)$ and Pacific men $(71 \%, 82 \%)$ in both cohorts.

Conclusions Policy should focus on reducing the acquisition and prevalence of $H$. pylori infection in these populations.
\end{abstract}

Keywords Noncardia cancer - Gastric cancer - Inequity · Disparity $\cdot$ Chronic infection

\section{Introduction}

Indigenous inequalities in gastric cancer incidence affect almost every indigenous population, many of whom live in poor socioeconomic circumstances [1]. Disproportionately

Electronic supplementary material The online version of this article (doi:10.1007/s10120-016-0671-8) contains supplementary material, which is available to authorized users.

Andrea M. Teng

andrea.teng@otago.ac.nz

1 Department of Public Health, University of Otago, PO Box 7343, Wellington, New Zealand higher gastric cancer incidence and mortality rates are seen in indigenous populations from the circumpolar region, the USA, South America, Australia, and New Zealand [1]. A greater proportion of gastric cancers in indigenous and ethnic minority groups are in the distal part of the stomach [1], the subsite strongly associated with Helicobacter pylori infection.

H. pylori is carcinogenic [2] and has been estimated to cause $89 \%$ of distal gastric cancers [3]. Prevalence differs considerably by ethnicity, and indigenous populations are disproportionately affected [4-6]. For example, in earlier work we found that Māori H. pylori prevalence was nearly double and Pacific people's $H$. pylori prevalence was nearly 2.5 times higher than that of European people in New Zealand [6]. It is not clear, however, how much of the excess gastric cancer in indigenous and marginalized ethnic groups is explained by $H$. pylori infection $[1,7]$. For example, the contribution of genetic factors to the excess incidence of gastric cancer among Māori has received considerable attention $[8,9]$. A clearer understanding of the drivers of gastric cancer inequalities is crucial for informing prevention measures. This study aims to estimate the extent to which $H$. pylori infection contributes to indigenous and ethnic inequalities in male gastric cancer incidence.

\section{Methods}

Gastric cancer incidence was obtained by ethnicity and age from the New Zealand Census Mortality and Cancer Trends Study. This is a record linkage study of complete population census and national cancer registrations for cohorts between 1981 and 2004 [10]. For men born in 1926-1940, there were 5.1 million person-years of follow- 
up and 1254 cases of gastric cancer during the study period. For men born in 1941-1955, there were 7.6 million personyears of follow-up and 442 cases.

Age-standardized incidence rates of distal gastric cancer were calculated for Māori (the indigenous population of New Zealand, composing $15 \%$ of the population), Pacific peoples (immigrants and their descendants from the Pacific Islands, composing 7\% of the population), and European/ other peoples (i.e. non-Māori, non-Pacific, and non-Asian individuals, composing $76 \%$ of the population). The ethnic differences in distal gastric cancer attributable to $H$. pylori infection were estimated by comparison of the baseline age-standardized rate ratio (SRR; Māori men compared with European/other men) with an SRR calculated as though all distal gastric cancer cases occurred among the H. pylori positive population $\left(\mathrm{SRR}_{\mathrm{HP}}\right)$ [6] (see the electronic supplementary material). The excess rate ratio proportion $\left[\left(\mathrm{SRR}-\mathrm{SRR}_{\mathrm{HP}}\right) /(\mathrm{SRR}-1)\right]$ was the primary result of this analysis, being the proportion of the excess risk of gastric cancer that is "explained" by H. pylori infection.

A series of sensitivity analyses were performed to assess the impact of our assumptions about the proportion of cancers that are distal, the prevalence of $H$. pylori infection, and the population standard used for age standardization. Quantitative bias analysis methods to adjust the data for confounding by smoking were also undertaken. Details of these sensitivity analyses are provided in the electronic supplementary material, and the results were not substantially affected.

\section{Results}

The contribution of $H$. pylori to gastric cancer differences by ethnicity was substantial and consistent across both birth cohorts (Fig. 1, Table 1). In both cohorts, the contribution of $H$. pylori was greatest in the Pacific population at $71 \%$ and $82 \%$ of the relative difference in distal gastric cancer rates in the two cohorts born in 1924-1940 and in 1941-1955 respectively compared with the European/other population. For Māori the $H$. pylori contribution was estimated to be $50 \%$ and $61 \%$ of the relative differences.

\section{Discussion}

We estimate that more than half of the excess distal gastric cancer incidence in Māori men and more than two thirds of that in Pacific men in New Zealand can be explained by H. pylori infection. Several factors have been proposed as contributors to the excess burden of gastric cancer in indigenous populations $[1,11]$, including poor nutrition
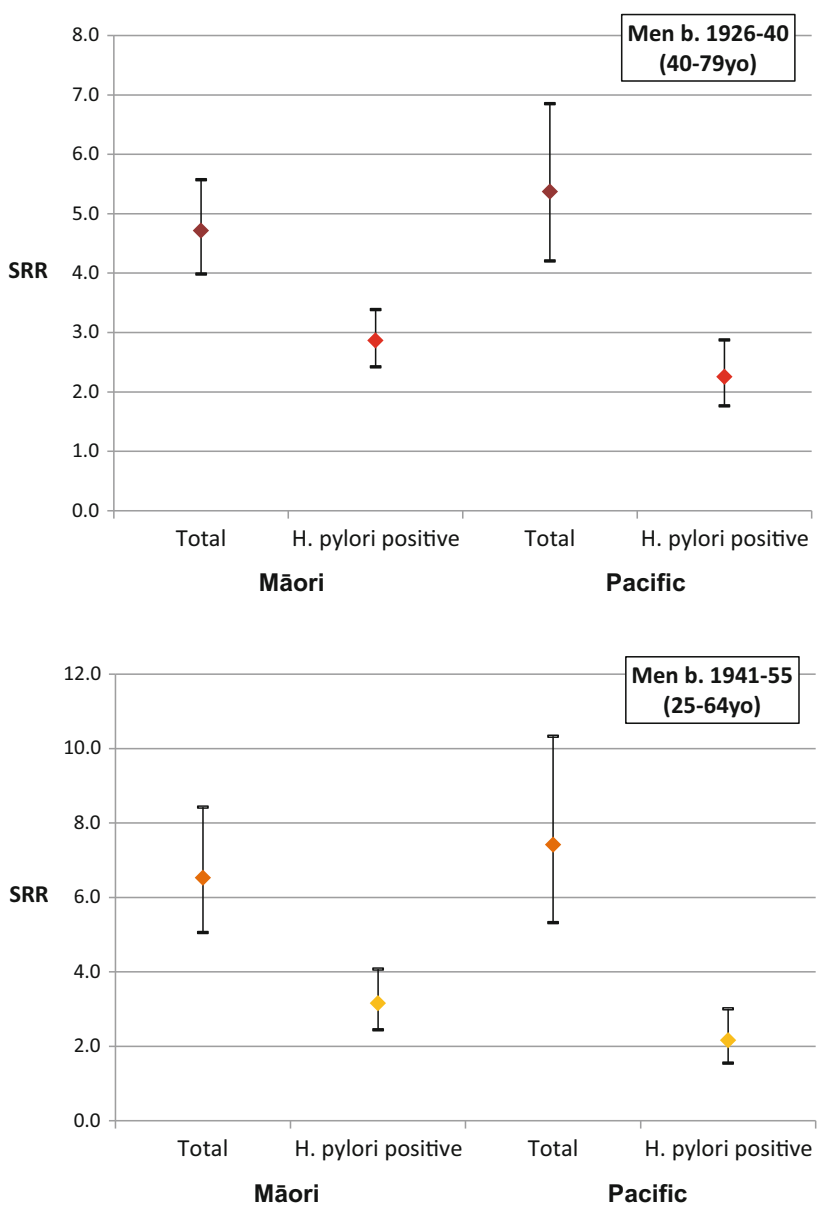

Fig. 1 Age-standardized distal gastric cancer incidence rate ratios (SRRs) comparing Māori and Pacific men with European/other men in two birth cohorts. The SRRs are presented unadjusted and adjusted for Helicobacter pylori infection, by the assumption that all distal gastric cancer cases occurred in men who were $H$. pylori positive and recalculation of the SRRs. ( $y o$ = years old)

and sanitation, excess salt, inadequate fruit and vegetable intake, and genetic predisposition. Our findings suggest that $H$. pylori infection explains most of the association, although the other factors mentioned may interact with or share a common causal pathway with $H$. pylori. It is likely that these findings can be generalized to Māori and Pacific women and to other indigenous and ethnic groups with high $H$. pylori prevalence and high gastric cancer incidence rates.

This report is one of the first to quantify the contribution of $H$. pylori to ethnic inequalities in gastric cancer incidence. Our results, however, may have been underestimated because of nondifferential measurement bias relating to $H$. pylori infection. The serology test does not distinguish the length of exposure to chronic infection, the intensity of infection, or the malignant potential of the subtype of $H$. pylori acquired. H. pylori seronegativity 
Table 1 Relative ethnic inequalities in distal gastric cancer incidence in Māori and Pacific men each compared with European/other men, calculated by restriction of the at-risk population to those who were Helicobacter pylori seropositive

\begin{tabular}{|c|c|c|c|c|c|c|c|}
\hline $\begin{array}{l}\text { Birth cohort, } \\
\text { and age }\end{array}$ & Ethnicity & $\begin{array}{l}\text { Gastric cancer } \\
\text { incidence } \\
1981-2004 \\
(\text { per 100,000) }\end{array}$ & $\begin{array}{l}\text { Distal gastric } \\
\text { cancer incidence } \\
\text { estimate } \\
(\text { per } 100,000)^{\mathrm{a}}\end{array}$ & $\begin{array}{l}\text { Rate ratio of } \\
\text { distal cancer }\end{array}$ & $\begin{array}{l}\text { Estimated rate } \\
\text { of distal cancer } \\
\text { among } H . \text { pylori } \\
\text { positive men }{ }^{c}\end{array}$ & $\begin{array}{l}\text { Rate ratio } \\
\text { adjusted for } \\
\text { H. pylori }\end{array}$ & $\begin{array}{l}\text { Excess rate ratio } \\
\text { proportion due } \\
\text { to } H \text {. pylori }(\%)\end{array}$ \\
\hline \multirow[t]{3}{*}{$\begin{array}{l}1926-1940 \\
\text { (40-79 years) }\end{array}$} & $\begin{array}{l}\text { European/ } \\
\text { other }\end{array}$ & 20.8 & 10.6 & 1 & 30.2 & 1 & \\
\hline & Māori & 57.4 & 49.9 & $4.71(3.99-5.57)$ & 86.5 & $2.86(2.42-3.39)$ & 50 \\
\hline & Pacific & 64.6 & 56.8 & $5.37(4.21-6.85)$ & 68.1 & $2.25(1.77-2.88)$ & 71 \\
\hline \multirow[t]{3}{*}{$\begin{array}{l}\text { 1941-1955 } \\
\text { (25-64 years) }\end{array}$} & $\begin{array}{l}\text { European/ } \\
\text { other }\end{array}$ & 4.1 & 2.1 & 1 & 10.2 & 1 & \\
\hline & Māori & 15.6 & 13.6 & $6.53(5.06-8.43)$ & 32.0 & $3.16(2.44-4.07)$ & 61 \\
\hline & Pacific & 17.5 & 15.4 & $7.42(5.32-10.3)$ & 21.9 & $2.16(1.55-3.01)$ & 82 \\
\hline
\end{tabular}

${ }^{a}$ Using the proportion of gastric cancer that was distal, from Biggar et al. [8]

b The $95 \%$ confidence interval is given in parentheses.

c Assuming $H$. pylori is a necessary factor for distal gastric cancer cases in all ethnic groups, the rates among $H$. pylori positive men are just the distal gastric cancer incidence in the total ethnic group divided by the $H$. pylori seroprevalence.

${ }^{\mathrm{d}}$ The rate ratios calculated with the estimated rate of distal cancer among $H$. pylori positive men

may be associated with severe atrophic gastritis or intestinal metaplasia caused by H. pylori infection; and thus the high risk of gastric cancer with these mucosal changes may also result in a slight underestimation of the impact of $H$. pylori on gastric cancer [12]. It is possible too that $H$. pylori infection is correlated with confounders such as smoking. However, we think this alternative hypothesis is unlikely. For example, our sensitivity analysis for "residual mediation" by smoking explained little more of the ethnic difference. We assumed that all distal cancers occur in people who have H. pylori infection. This assumption may have inflated our results slightly; however, it is the best estimate of $H$. pylori contribution we could calculate given the evidence available, and in our view is likely to be more than offset by possible nondifferential misclassification of $\mathrm{H}$. pylori status. Our findings were robust in relation to the sensitivity analyses we performed (see the electronic supplementary material).

H. pylori is likely to be the major contributor to excess Māori and Pacific gastric cancer incidence. Pro-equity interventions should be developed to reduce the prevalence of $H$. pylori infection, particularly in high-risk groups. This includes measures that address overcrowding and acquisition of infection [13, 14], and H. pylori eradication strategies, particularly if stronger evidence is produced that shows the benefits from screening outweigh any harms $[15,16]$.

Acknowledgements We thank June Atkinson for assistance with the New Zealand Cancer Trends data. We also thank the New Zealand Cancer Society for its financial contribution to cover costs for accessing data.

\section{Compliance with ethical standards}

Conflict of interest The authors declare that they have no competing interests.

Ethical standards All procedures followed were in accordance with the ethical standards of the responsible committee on human experimentation (institutional and national) and with the Helsinki Declaration of 1964 and later versions. CancerTrends was granted ethical approval at the University of Otago (reference 04/10/093). This study used nonidentifying administrative data.

\section{References}

1. Arnold M, Moore SP, Hassler S, et al. The burden of stomach cancer in indigenous populations: a systematic review and global assessment. Gut. 2014;63:64-71.

2. Schistosomes, liver flukes and Helicobacter pylori. IARC Working Group on the Evaluation of Carcinogenic Risks to Humans. Lyon, 7-14 June 1994. IARC Monogr Eval Carcinog Risks Hum. 1994;61:1-241.

3. Plummer M, Franceschi S, Vignat J, et al. Global burden of gastric cancer attributable to Helicobacter pylori. Int J Cancer. 2015;136:487-90.

4. Goodman KJ, Jacobson K, van Zanten SV. Helicobacter pylori infection in Canadian and related Arctic Aboriginal populations. Can J Gastroenterol. 2008;22:289.

5. Perez-Perez GI, Rothenbacher D, Brenner H. Epidemiology of Helicobacter pylori infection. Helicobacter. 2004;9(Suppl 1):1-6.

6. McDonald AM, Sarfati D, Baker MG, et al. Trends in Helicobacter pylori infection among Maori, Pacific, and European Birth cohorts in New Zealand. Helicobacter. 2015;20:139-45.

7. Blair V, Kahokehr A, Sammour T. Cancer in Māori: lessons from prostate, colorectal and gastric cancer and progress in hereditary stomach cancer in New Zealand. ANZ J Surg. 2013;83:42-8. 
8. Biggar M, Srinivasa S, Wickramarachchi B, et al. Gastric cancer location and histological subtype in Pacific people and Māori defies international trends. N Z Med J. 2011;124:1-6.

9. Fraser AG. Helicobacter pylori: a historical perspective 1983-2003. N Z Med J. 2004;117(1194):1-7.

10. Blakely T, Shaw C, Atkinson J, et al. Cancer trends: trends in cancer incidence by ethnic and socioeconomic group, New Zealand 1981-2004. Wellington: University of Otago and Ministry of Health; 2010.

11. Parkin DM, Boyd L, Walker LC. The fraction of cancer attributable to lifestyle and environmental factors in the UK in 2010. Br J Cancer. 2011;105(Suppl 2):S77-81.

12. Terasawa T, Nishida H, Kato K, et al. Prediction of gastric cancer development by serum pepsinogen test and Helicobacter pylori seropositivity in Eastern Asians: a systematic review and metaanalysis. PLoS One. 2014;9:e109783.

13. McDonald AM. Casting a long shadow: the role of household crowding on Helicobacter pylori infection, and excess stomach cancer incidence among Māori and Pacific people. Master of public health thesis. Wellington: Department of Public Health, University of Otago Wellington; 2013. Available via http://hdl. handle.net/10523/5968.

14. Baker MG, McDonald AM, Zhang J, et al. Infectious diseases attributable to household crowding in New Zealand: a systematic review and burden of disease estimate. Wellington; He Kainga Oranga/Housing and Health Research Programme, University of Otago and Ministry of Health; 2013.

15. International Agency for Research on Cancer. Helicobacter pylori eradication as a strategy for preventing gastric cancer. IARC working group report volume 8. Lyon: International Agency for Research on Cancer; 2014.

16. Ford AC, Forman D, Hunt R, et al. Helicobacter pylori eradication for the prevention of gastric neoplasia. Cochrane Syst Database Rev. 2015;(7):CD005583. 